\title{
DA COLONIALIDADE DO SABER PARA A VALORIZAÇÃO DAS EPISTEMOLOGIAS DO SUL: POR UMA EDUCAÇÃO EMANCIPATÓRIA PARA OS DIREITOS HUMANOS
}

\author{
Sirval Martins dos Santos Júnior ${ }^{1}$
}

Resumo: O presente artigo tem como objetivo precípuo de reafirmar a importância da valorização das epistemologias do sul a partir de uma educação emancipatória dos Direitos Humanos enquanto estratégia de reafirmação da cidadania. Utilizou-se o método dialético, por propiciar a interpretação dos fenômenos sociais por intermédio de princípios, leis e categorias de análise através da contradição. Observou-se que a educação jurídica e não jurídica a partir da ótica dos Direitos Humanos será capaz de propiciar um diálogo intercultural e de reconhecimento das lutas sociais e das epistemologias de grupos historicamente invisibilizados e excluídos.

Palavras-chave: Colonialidade; epistemologias do sul; educação; direitos humanos; emancipação.

\section{FROM THE COLONIALITY OF KNOWLEDGE TO THE VALORIZATION OF SOUTHERN EPISTEMOLOGIES: TOWARDS AN EMANCIPATORY EDUCATION FOR HUMAN RIGHTS}

\begin{abstract}
The main objective of this article is to reaffirm the importance of valuing the epistemologies of the south from an emancipatory education of human rights as a strategy to reaffirm citizenship. The dialectical method was used, as it allows for the interpretation of social phenomena by means of principles, laws, and categories of analysis through contradiction. It was observed that legal and non-legal education from the perspective of Human Rights will be able to propitiate an intercultural dialogue and the recognition of social struggles and epistemologies of historically invisibilized and excluded groups.
\end{abstract}

Keywords: Coloniality; epistemologies of the south; education; human rights; emancipation

\section{INTRODUÇÃO}

\footnotetext{
${ }^{1}$ Mestre em Direitos e Garantias Fundamentais na Faculdade de Direito de Vitória (FDV), sendo bolsista institucional do PPGD/FDV. Pesquisador do Grupo de Pesquisa Invisibilidade social e energias emancipatórias em Direitos Humanos. Pós-Graduando em Direito do Trabalho e Previdenciário na Pontifícia Universidade Católica (PUC-MG). Graduado em Direito pela FDV, com bolsa do Programa Universidade para Todos (ProUni), tendo cursado um semestre na Faculdade de Direito da Universidade Nova de Lisboa (FDUNL) em intercâmbio estudantil internacional. Técnico em Administração pelo Instituto Federal do Espírito Santo (Ifes). Assessor da Secretaria Estadual de Direitos Humanos do Governo do Estado do Espírito Santo. Advogado $\mathrm{OAB} / \mathrm{ES} \mathrm{n}^{\circ}$ 33.073. Membro da Comissão da Dignidade da Advocacia da OAB/ES. Atuante nas áreas de Direito Constitucional, Direito Administrativo, Direitos Humanos, Direito do Trabalho e Previdenciário. E-mail: sirvaljr@gmail.com
}

Revista de Pesquisa e Educação Jurídica | e-ISSN: 2525-9636 | Encontro Virtual | v. 7 | n. 2 | 
A educação para os Direitos Humanos é condição sine qua non para romper com a exclusão e as invisibilidades oriundas da lógica capitalista e colonizadora. As lutas contra hegemônicas das minorias devem ser reconhecidas e valorizadas, sobretudo quando se tratado modo de produção e de reprodução do conhecimento científico, com o rompimento de grilhões históricos do eurocentrismo enquanto projeto de poder e dominação.

A teoria da colonialidade do poder busca explicar esse pensamento cartesiano e a pretensão hegemônica que deixa seus ratos até a modernidade. A subcidadania, a desigualdade social, econômica e cultural das periferias existentes na sociedade, sobretudo a brasileira, são retratos das consequências de um passado explorador, acrítico e de imposiçãode uma ordem econômica e cultural nos países colonizados, como o Brasil.

Outra grave consequência é que a pesquisa científica e a academia, em sua esmagadora maioria, enaltecem os pensadores e teóricos europeus. Daí surge à relevância em pesquisar acerca da decolonialidade do poder e por uma reafirmação das epistemologias do sul, para o rompimento com o tradicionalismo eurocêntrico que impera nas universidades e instituições de ensino.

Dessa forma, questiona-se: quais as formas de romper com os paradigmas impostos pela colonialidade do poder e o pensamento cartesiano eurocêntrico que inviabilizou a existência, a valorização e o reconhecimento das Epistemologias do Sul? Seria o investimento em políticas públicas educacionais emancipatórias para os Direitos Humanos, de modo a propiciar o diálogo intercultural e o reconhecimento das diferenças, sob um ideal de igualdade e de justiça, enquanto a única forma para romper com tal paradigma?

Para obter as respostas do problema de pesquisa, apropriou-se do método dialético, uma vez que é propicia analisar os fenômenos por uma ação recíproca, da contradição e da mudança dialética que ocorre no seio social (MARCONI, LAKATOS, 2018). Esse método propicia uma forma de interpretar os fenômenos sociais que se travestem por princípios, leis e categorias de análise (RICHARDSON, 2017). Também foi utilizada a técnica da pesquisa bibliográfica a partir de bases teóricas consolidadas sobre o assunto, a saber: Aristóteles; Ballestrin; Bordieu; Kant; Mignolo; Quijano; Santos; Segatto, dentre outros.

$\mathrm{Na}$ primeira seção, abordar-se-á acerca da teoria da colonialidade do poder de Anibal Quijano; na segunda seção, será proposto um pensamento que reafirme as epistemologias do sul, superando o pensamento colonial e cartesiano; por último, não 
menos importante, a terceira seção tratará sobre a necessidade do giro decolonial na epistemologia jurídica para a promoção de uma educação para os Direitos Humanos enquanto uma prática emancipatória e cidadã.

\section{A TEORIA DO COLONIALIDADE DO PODER}

A teoria de Anibal Quijano (1991) está pautada na dependência e subordinação dos países do hemisfério sul aos desenvolvidos, com os olhos voltados aos países latinoamericanos, nomeando-os como uma "periferia capitalista". Ao vislumbrar essa dependência econômica e dominação quase que absoluta que possui raízes desde a antiguidade e perdura até a modernidade, Quijano busca a criação de um pensamento próprio, independente, heterodoxo, sem as amarras doutrinárias e dogmas europeias que foram importadas e incutidas no ideário social dos países colonizados.

Trata-se de um processo contínuo, inacabado, em que se torna impossível reafirmar o caráter permanente na busca dessa desvinculação teórica e social, por serem movimentos dinâmicos de caminhos e descaminhos, de continuidade e descontinuidade. Não é um tema que surgiu na atualidade, ao contrário, tampouco irá se acabar como uma simples operação matemática ante sua complexidade e sua perpetuação no tempo. A filosofia, a antropologia, a sociologia e a história crítica, enquanto áreas do conhecimento das ciências sociais possuem relevância extrema ao compreender e analisar tal fenômeno. Acerca disso, Quijano (1991, p. 54-55) alude que:

\footnotetext{
Admito que o debate latino-americano dos últimos vinte ou vinte e cinco anos estevesob o predomínio dos problemas chamados econômicos, sociais e políticos; mas não me parece que os outros problemas tenham estado ausentes desse debate. Primeiro, porque cheguei à conclusão de que, quando a gente fala de ciências sociais, de algum estranho modo, menciona apenas a sociologia, digamos tecnocrática, e a economia e talvez os chamados cientistas políticos. Esquece, no entanto, a antropologia e a história. Diria, pois, que não sinto que, no movimento de minha reflexão, o cultural tenha estado ausente, nem como tema, nem como questão, embora é certo que, em alguns períodos, pelas características do debate latino- americano, seguramente colocava muito mais ênfase nos outros aspectos.
}

O legado de Quijano atravessa as questões que erode a crença cega nos valores eurocêntricos para a produção das epistemologias, do saber e do fazer acadêmico, 
fazendo com que se possua uma percepção consciente e lúcida do estreito vínculo entre racismo, eurocentrismo, capitalismo e modernidade, articulação esta que se denomina “colonialidade" (SEGATTO, 2015). No que tange ao padrão de poder, Quijano (2002, p. 04) define amodernidade e a colonialidade em quatro itens, a saber:

1) a colonialidade do poder, isto é, a ideia de "raça" como fundamento do padrão universal de classificação social básica e de dominação social; 2) o capitalismo, como padrão universal de exploração social; 3) o Estado como forma central de controle da autoridade coletiva e o moderno Estado-nação como sua variante hegemônica; 4) o eurocentrismo como forma hegemônica de controle da subjetividade/intersubjetividade, em particular no modelo de produzir conhecimento.

O modo de produzir conhecimento sempre esteve pautado na elaboração intelectual do processo da modernidade, a partir de um caráter de um padrão mundial de poder, a saber: colonial, moderno, capitalista e eurocentrado, estabelecido a partir da América, o que traduz, portanto, a definição daquilo que se chama de "eurocentrismo" (QUIJANO, 2005, p. 115). Nesse contexto, as identidades das populações estão submetidas à hegemonia eurocêntrica que define o que é e o que não é conhecimento, construindo um imaginário colonizado que traduz em uma mutilação epistemológica (QUIJANO, 2005, p. 115). Tal prática traduz em uma impossibilidade de realizar a ecologia de saberes e estabelece linhas abissais entre o "lado de lá" e o "lado de cá" (SANTOS, 2010). Nesse sentido,

Essa colonialidade do controle do trabalho determinou a distribuição geográfica de cada uma das formas integradas no capitalismo mundial. Em outras palavras, determinou a geografia social do capitalismo: o capital, na relação social de controledo trabalho assalariado, era o eixo em torno do qual se articulavam todas as demais formas de controle do trabalho, de seus recursos e de seus produtos. Isso o tornava dominante sobre todas elas e dava caráter capitalista ao conjunto de tal estrutura de controle do trabalho. Mas ao mesmo tempo, essa relação social específica foi geograficamente concentrada na Europa, sobretudo, e socialmente entre os europeus em todo o mundo do capitalismo. E nessa medida e dessa maneira, a Europa e o europeu se constituíram no centro do mundo capitalista. (QUIJANO, 2005, p. 110)

Muito além da busca da expansão colonial imperialista de terras antes não "descobertas", da exploração de metais preciosos, da produção em larga escala com mão de obra barata, do novo modo de pensar, o objetivo era padronizar uma única raça e cultura dominante em todo o mundo: a dos brancos europeus. É importante ressaltar que esse “privilégio oculto, disfarçado de triunfo celebratório da espécie humana, que se arroga o 
poder e o conhecimento que permitem classificar e dominar o resto da humanidade é a colonialidade do poder" (MIGNOLO, 2006, p. 676-677).

O racismo para com a América Latina foi, por muitos anos, ocultado, invisibilizado, não sendo objeto de pesquisa crítica pela academia. Essa discussão contribui como referência para a compreensão da modernidade ocidental, já que a cultura, a educação, a forma de produção acadêmica e social não possui traços genuínos e próprios, mas sim europeu. Sobre a ideia de raça, Quijano (2006, p. 81) define como:

[...] uma estrutura biológica que diferencia a população humana entre inferior e superior porque está associada às capacidades respectivas de produção cultural e intelectual em particular. [...] Sobre essa base e durante cinco séculos seguintes a população do planeta foi classificada entre raças superiores e inferiores. E essa classificação foi articulada com o controle do trabalho e com o controle da autoridade e da subjetividade.

O capitalismo, dessa forma, deu origem às novas periferias colonizadas, a partir de uma nova divisão social do trabalho, de acordo com os interesses dos colonizadores, se constituindo a Europa como o centro do mundo capitalista. A história política dos países da América do Sul possui cordão umbilical no critério de exclusão, sem qualquer tipo de oportunidade de democratização das relações sociais de grande parte da população, sobretudo aqueles que não serviam o capital, tampouco contribuíram para o acúmulo de riquezas, como, por exemplo, índios, negros e mestiços. A ética democrática, nesses países, ocorreu de forma tardia por estar imbricada nas condições de dominação, exploração e do conflito, da dualidadedas classes sociais de proletariado e da burguesia. Quanto a isso,

A teoria de Quijano sobre a colonialidade propõe uma concepção da diferenciação colonial e epistêmica, onde a colonialidade se transfere do âmbito do poder para o campo do saber, construindo a colonialidade do saber que age de forma a manter a hegemonia eurocêntrica como perspectiva superior do conhecimento. A formação do contexto internacional de sistema-mundo e do paradigma moderno/colonial faz com que o fim do colonialismo não resulte no fim da colonialidade. Mesmo após a independência do jugo colonial de outras nações, ela permanece permeando asrelações. Desse modo, o jogo de poder e dominação em diversos aspectos se mantêm como no âmbito do conhecimento. As ciências sociais se constroem neste espaço de dominação e são atravessadas por essas relações de poder. (SILVA,BALTAR E LOURENÇO, 2018, p. 70)

Para além do critério econômico, os europeus se apropriavam das instituições estatais, da igreja e também do monopólio do saber, da formação jurídica, sobretudo, para manter a sua perpetuação no poder e no controle da produção jurídica, para servir ao seu bel prazer. O direito brasileiro, assim como a educação jurídica, também tem uma grande 
influência europeia, uma vez que, naquela época, apenas os filhos dos burgueses tinham condições econômicas de sair do país para cursar o ensino superior na Europa.

Ademais, quando se iniciou as universidades no Brasil, fora importado até mesmo a forma de ensinar, a partir de uma educação bancária, conforme pregada por Paulo Freire, no método Coimbrão, em que o aluno era um mero depósito de conhecimento, sem formação crítica, humanística e reflexiva, numa relação puramente verticalizada para com o professor.

Outra herança da colonialidade foi à pretensa ideia de que o Direito, por si só, possui o condão de resolver todos e quaisquer tipos de problemas e/ou conflitos, sendo autossuficiente. Este pensamento Kelseniano, pauta-se na Teoria Pura do Direito, na tentativa de expurgar todos e quaisquer tipos de influências de outras áreas do conhecimento noDireito, ignorando, totalmente, a complexidade do mundo moderno.

Nessa linha histórica, após a importação do modelo de ensino do Direito, o novo período histórico que também trouxe grandes efeitos no contexto da América Latina foi o da Revolução Industrial, bem como atualmente como o fenômeno da globalização, da pósmodernidade, do neoliberalismo, apresentam-se como tendências de reconcentração do poder,oriundo das raízes coloniais, de modo a impor a hegemonia de exploração do capital humano, tecnológico e econômico.

Muito embora não seja o objeto do presente trabalho, é preciso ressaltar que a onda do neoliberalismo e do neoconservadorismo pujante possuem os mesmos objetivos da colonialidade do poder, tal qual do imperialismo e da colonização histórica, enquanto dominadores, seja por donos de grandes corporações financeiras, seja por governantes de regimes despóticos-burocráticos.

Essa visão universalista, global e etnocentrista não se coadunam com os preceitos eos cânones interpretativos da Constituição Brasileira de 1988, tampouco com os Tratados Internacionais que o Brasil e diversos países do mundo são signatários. Essa colonialidade, no entanto, ainda é difundida de forma mascarada, velada, a partir de um projeto de poder imperialista e de dominação de uma nação sob a outra, desrespeitando as particularidades de cada povo, sem viabilizar o diálogo intercultural dos direitos humanos.

É preciso que haja uma desvinculação dos conceitos veiculados pela realidade eurocêntrica a partir de uma desobediência epistêmica, para haver a "libertação" das ciências sociais latino-americanas e resgatar a humanidade, as características genuínas e a 
humanidadeque, por tanto tempo, foram negadas aos povos. É necessária a valorização de culturas, costumes e subjetividades que foram anuladas pelo processo colonial. Não se trata, contudo, de uma campanha discriminatória e de desqualificação aos ideais postos pelos europeus, mas a partir da criação novos e múltiplos olhares sobre as realidades, sem generalizações e que o oprimido tome o lugar do opressor (MIGNOLO, 2008, p. 290).

Torna-se evidente, portanto, que o giro decolonial é de suma importância para que haja a devida valorização das epistemologias do sul, a partir de olhares múltiplos das nações e dos povos que o compõe. Além dessa reafirmação, a produção acadêmica contra hegemônica é indispensável, para que a pesquisa científica auxilie o Estado-nação a promoção de políticas públicas inclusivas para a redução das desigualdades e das invisibilidades, que será tratado no capítulo a seguir.

\section{PARA ALÉM DA COLONIALIDADE E DO SABER CARTESIANO: POR UMA REAFIRMAÇÃO DAS EPISTEMOLOGIAS DO SUL}

Como mencionado no capítulo anterior, a América Latina, assim como os demais continentes e países do hemisfério sul, que foram, em sua esmagadora maioria, colonizados pelos europeus ou pelos estadunidenses, tiveram sua cultura quase que exterminada, sendo implantada, de forma quase que obrigatória, uma nova ordem social, na órbita social, econômica, cultural e, sobretudo, a epistemológica. Essa perspectiva de perpetuação das epistemologias europeias eliminou a racionalidade crítica e consciente no modo de produção ereprodução do conhecimento dos países colonizados, de modo a não se levar em consideração o seu próprio contexto cultural e político, trazendo-lhes consequências irreparáveis que reverberam na atualidade.

O colonialismo foi uma forma de dominação epistemológica, uma vez que o saberpoder conduziu à supressão de muitas formas de saber dos povos e nações colonizados, relegando muitos outros saberes para um espaço de subalternidade (SANTOS; MENESES, 2010, p. 7). A dominação epistemológica da relação desigual do "saber-poder" oriunda do colonialismo, segundo a teoria de Anibal Quijano, levou com que as particularidades de diversos povos fossem suprimidas. Todavia, para compreender melhor o objetivo deste capítulo, faz-se necessário compreender o que se compreende acerca da expressão 
"Epistemologias do Sul":

Trata-se do conjunto de intervenções epistemológicas que denunciam a supressão dos saberes levada a cabo, ao longo dos últimos séculos, pela norma epistemológica dominante, valorizam os saberes que resistiram com êxito e as reflexões que estes têm produzido e investigam as condições de um diálogo horizontal entre conhecimentos. A esse diálogo entre saberes chamamos ecologias de saberes (SANTOS; MENESES, 2010, p. 7).

Não se trata de novos saberes, novas epistemologias. Trata-se, na verdade, da valorização do conhecimento que, por diversos anos, foram invisibilizados, ocultados e ausentes perante a vasta dominação epistemológica europeia. Não é de se causar estranheza caso, por exemplo, você questione, em uma aula de filosofia, quais são os filósofos mais reconhecidos e estudados do mundo. Os alunos, por sua vez, sempre responderão, a guisa de exemplo, "Marx", "Foucault", “Jhon Locke", dentre outros pensadores europeus. Por outro lado, causará muito espanto se a resposta for algum pensador da América Latina ou atémesmo do Brasil.

O exemplo acima só demonstra empiricamente que a perpetuação da epistemologia europeia ainda é um tanto quanto dominante e ecoa efeitos na modernidade, no ideário, inclusive, daqueles que ainda não possuem formação acadêmica. É uma forma de produção e reprodução de conteúdo, sem que haja a devida valorização e o diálogo intercultural para com aqueles que produzem o conhecimento no seio social em que se vive. A supressão de particularismos e da produção de conhecimento local é denominado "epistemicídio". Essa forma de exclusão e de silenciamento de povos e culturas é apenas uma consequência do colonialismo e do capitalismo emergente desde a antiguidade até os dias atuais.

Pode-se dizer, dessa forma, que o pensamento moderno ocidental é abissal, conforme Santos (2010), em um sistema de dois mundos, divididos entre visíveis e invisíveis, criando abismos estruturais entre culturas, povos, economias, sociedades e também no modo deeducar e de produzir conhecimentos. Há linhas radicais que dividem a realidade social em dois universos distintos, a saber: o universo "deste lado da linha" que traduz o positivismo cartesiano europeu que busca incessantemente pela sua autonomia e dominação dos povos, eo "outro lado da linha" que designa os excluídos, os invisibilizados, os excluídos, os sub- humanos, os subcidadãos, criando uma "sociologia das ausências" (SANTOS, 2010).

Boaventura de Sousa Santos traduz sua teoria no texto "Para além do pensamento 
abissal: das linhas globais a uma ecologia de saberes", sobretudo no que tange ao pensamento abissal do mundo moderno ocidental, nas seguintes palavras:

O pensamento moderno é um pensamento abissal. Consiste num sistema de distinções visíveis e invisíveis, sendo que as invisíveis fundamentam as visíveis. As distinções invisíveis são estabelecidas através de linhas radicais que dividem a realidade social em dois universos distintos: o universo ,deste lado da linha ${ }^{e e}$ e universo „do outro lado da linha ${ }^{e e}$. A divisão é tal que o „outro lado da linha desaparece enquanto realidade, torna-se inexistente, e é mesmo produzido como inexistente (SANTOS, 2010, p. 32).

A negação daqueles que estão do "outro lado da linha" é condição primordial para a formação da modernidade para que os colonizadores possam reafirmar a sua universalidade abstrata e o seu modo capitalista de produção. Por isso, todos os saberes e as práticas produzidos pelo "outro lado da linha" são anulados e desaparecem para a prevalência da monocultura e o monopólio linear, cartesiano e da naturalização das invisibilidades e da legitimar a diferença.

Nesse mesmo caminho, pode-se afirmar que se trata de uma violência simbólica, conforme Bordieu (1998), por ser vista como uma forma de coação que se apoia em uma imposição determinada, na criação contínua de crenças no processo de socialização, que leva o indivíduo a se posicionar no seio social, seguindo padrões e costumes do discurso dominante, numa relação de interdependência, já que há uma cumplicidade entre quem sofre equem a pratica, sem que os envolvidos tenham consciência da violência ali praticada.

É preciso tomar consciência e reconhecer a presença das linhas abissais, da desigualdade e das invisibilidades para se pautar em uma luta contra hegemônica. Para a superação dessa lógica excludente, emerge, então, a necessidade de um pensamento "pósabissal" a qual Santos (2010, p. 51-52) alude que:

O pensamento pós-abissal parte da ideia de que a diversidade do mundo é inesgotável e que esta diversidade continua desprovida de uma epistemologia adequada. Por outras palavras, a diversidade epistemológica do mundo continua por construir. [...] O pensamento pós-abissal parte do reconhecimento de que a exclusão social no seu sentido mais amplo toma diferentes formas conforme é determinada por uma linha abissal ou não-abissal, e que, enquanto a exclusão abissalmente definida persistir, não será possível qualquer alternativa póscapitalista progressista.

Esta nova vanguarda traz a atenuação, a superação da sociologia das ausências, consequência do pensamento histórico linear, cartesiano e colonial. Em vez da 
singularidade, busca-se a pluralidade, em vez do monopólio, busca-se a dualidade, em vez da exclusão, busca-se a inclusão.

Para o rompimento dessa monocultura do saber científico e da produção de conhecimento, das linhas abissais, do pensamento cartesiano e colonial, Boaventura de Sousa Santos (2006) traça a necessidade da criação da "Ecologia dos Saberes", que é um conceito que busca promover o diálogo entre saberes diversos, das lutas sociais, da contínua construçãocoletiva das epistemologias e da valorização dos particularismos, por intermédio do dialogismo intercultural.

A ecologia dos saberes é um dos principais conceitos de Boaventura de Sousa Santos, sendo a proposta central da epistemologia do sul, em que reconhece a diversidade epistemológica do mundo, de modo tal a reconhecer o pensamento pluralista e propositivo. Assim, é possível afirmar que "a ecologia de saberes é um conjunto de epistemologias que partem da possibilidade da diversidade e da globalização contra hegemônicas e pretendem contribuir para as credibilizar e fortalecer" (SANTOS, 2008, p. 154).

Não há, nessa teoria, a hierarquia de um saber maior e um saber menor, um saber mais valioso e outro menos valioso, a verdade é que existem vários tipos de conhecimento, produzidos em diversos locais do mundo, por diversos povos, sob vários olhares e várias mãos. Nessa senda, é necessário propiciar um diálogo intercultural entre diversos saberes, entre as diversas culturas.

Esse diálogo intercultural só será possível a partir de uma hermenêutica diatópica, isto é, que os topoi (as premissas) de uma cultura, por mais fortes que sejam, são tão incompletos quanto à própria cultura que pertencem. É uma forma de reconhecer a própria incompletude que não é visível do interior da cultura, pois a aspiração à totalidade induz a quese tome a parte pelo todo (SANTOS, 2009). Quanto a isso, é imperioso afirmar que:

Num diálogo intercultural, a troca ocorre entre diferentes saberes que refletem diferentes culturas, ou seja, entre universos de sentido diferentes e, em grande medida, incomensuráveis. Tais universos de sentido consistem em constelações de topoi fortes. Os topoi são os lugares comuns retóricos mais abrangentes de determinada cultura. Funcionam como premissas de argumentação que, por nãose discutirem, dada a sua evidência, tornam possível a produção e a troca de argumentos. [...] A hermenêutica diatópica baseia-se na ideia de que os topoi de uma dada cultura, por mais fortes que sejam, são tão incompletos quanto a própriacultura a que pertencem. Tal incompletude não é vivível a partir do interior dessa cultura, uma vez que a inspiração à totalidade induz a que se tome a parte pelo todo. O objetivo da hermenêutica diatópica não é, porém, atingir a completude - um objetivoinatingível - mas, pelo contrário, ampliar ao máximo a 
consciência deincompletude mútua através de um diálogo que se desenrola, por assim dizer, com um pé numa cultura e outro, noutra. Nisto reside seu caráter diatópico. (SANTOS, 2006, p. 447, 448).

Esse diálogo intercultural pela hermenêutica diatópica, a partir da ecologia de saberes, busca a desconstrução, a abertura de espaços, práticas e conhecimentos. Isso ocorre também no âmbito das universidades, em que "a ecologia de saberes pode ser compreendida como um aprofundamento da pesquisa-ação e possui a missão e reorientar de forma solidáriaa relação entre universidade e sociedade” (SANTOS, 2011).

Os setores da sociedade, dessa forma, podem e devem ser coautores da produção desses conhecimentos de forma a fomentar práticas emancipatórias de populações que estão invisibilizadas e excluídas no seio social. As diferenças existem e, por isso, a produção acadêmica deve sempre visar alcançar o ideal da igualdade, tratando os desiguais na medida de suas desigualdades, para a promoção da justiça e de uma sociedade mais equânime. Isto é, nas palavras de Aristóteles, "tratar igualmente os iguais e desigualmente os desiguais na medida de sua igualdade". Nesse mesmo caminho, Boaventura de Santos registra suamáxima:

Temos o direito de ser iguais quando a nossa diferença nos inferioriza e temos o direito de ser diferentes quando a nossa igualdade nos descaracteriza. Daí a necessidade de uma igualdade que reconheça as diferenças e, de uma diferença que não produza, alimente ou reproduza as desigualdades (SANTOS, 1997).

O novo paradigma das Epistemologias do Sul existe e deve ser reafirmada como prática emancipatória para a promoção de uma educação libertadora para os Direitos Humanos, por intermédio de um diálogo intercultural. Trata-se de uma proposta de epistemologia subalterna, resistente e alternativa ao projeto hegemônico de dominação colonialista, patriarcal e capitalista que está em evidencia na sociedade, sob os vieses do neoliberalismo e do neoconservadorismo.

As Epistemologias do Sul superam o paradigma de que as Epistemologias do Norte são universais, para o reconhecimento de todos e quaisquer tipo de produção de conhecimento, seja do Ocidente ao Oriente, de Norte a Sul, de nível local, nacional e global, para diferenças que sejam horizontais e não verticais (SANTOS, 2014). Urge a necessidade de uma vanguarda pós-colonial, ou melhor, um movimento decolonial, enquanto um movimento político e intelectual. Quanto a isso:

Revista de Pesquisa e Educação Jurídica | e-ISSN: 2525-9636 | Encontro Virtual | v. 7 | n. 2 | 


\begin{abstract}
Neste sentido, defendemos que o argumento pós-colonial em toda sua amplitude histórica, geográfica e disciplinar percebe a diferença colonial e intercede pelo colonizado. Isto significa dizer que o argumento pós-colonial é em maior ou menor grau comprometido. Pelo argumento pós colonial o resgate da história, do conhecimento, do discurso, do sujeito e da memória do status "colonizado" nunca pretende, através de sua visibilidade e da vocalização, fortalecer o "outro" colonizador. Em termos de teoria política contemporânea, a relação colonial é uma relação antagônica e não agônica. (BALLESTRIN, 2012, p. 4).
\end{abstract}

Para a reafirmação das Epistemologias do Sul em detrimento da colonialidade do poder, do rompimento com o pensamento cartesiano e da pretensa universalidade hegemônicaeuropeia, é necessário que o giro decolonial ocorra de dentro para fora, a partir da promoção de um diálogo intercultural dos direitos humanos como prática emancipatória, para haver, de fato, a decolonialidade, a começar pela educação jurídica. Quanto a essa temática, será mais bem pormenorizada na próxima seção.

\title{
3 O GIRO DECOLONIAL NA EPISTEMOLOGIA JURÍDICA: EDUCAÇÃO PARA OS DIREITOS HUMANOS COMO UMA PRÁTICAEMANCIPATÓRIA
}

É necessária a construção de um pensamento pós-abissal que seja “[...] um pensamento alternativo e de alternativas" para admissão da diversidade do mundo, mas que seja desprovida de uma epistemologia adequada (SANTOS, 2010, p. 50). O pensamento pós- abissal é um:

\begin{abstract}
Um pensamento não-derivado, envolve ruptura radical com as formas ocidentais modernas de pensamento e ação. Em nosso tempo, pensar em termos não derivativos significa pensar a partir da perspectiva do outro lado da linha, precisamente por o outro lado da linha ser o domínio do impensável na modernidade ocidental. [...] um aprender com o Sul. [...] É uma ecologia, porque se baseia no reconhecimento da pluralidade heterogêneos (sendo um deles a ciência moderna) e em interações sustentáveis e dinâmicas entre eles sem comprometer a sua autonomia. A ecologia de saberes baseia-se na ideia de que o conhecimento é interconhecimento. (SANTOS, 2010, p. 53).
\end{abstract}

Um movimento que coaduna com o pensamento pós-abissal é o giro decolonial, termo cunhado por Nelson Maldonado-Torres em 2005. Este giro decolonial significa um movimento teórico e prático, político e epistemológico, frente à lógica da colonialidade. Esse movimento que envolve diversos teóricos residentes nos grandes centros e também

Revista de Pesquisa e Educação Jurídica | e-ISSN: 2525-9636 | Encontro Virtual | v. 7 | n. 2 | 
nas periferias da geopolítica de produção do conhecimento, questiona e faz árduas críticas ao eurocentrismo, o positivismo epistemológico, o neoliberalismo científico e o universalismo etnocêntrico (BALLESTRIN, 2013).

Essa ruptura paradigmática só alcançará êxito quando houver o questionamento da base escolar, dos regimes e dogmas incutidos na sociedade como verdades absolutas e também das práticas discursivas do direito e da educação. Há a necessidade de descolonizar o pensamento, o ensino e o conhecimento sobre os Direitos Humanos. O zelo e a efetivação dos Direitos Humanos, em nível internacional, ou ainda os Direitos e Garantias Fundamentais, em nível constitucional e nacional, é indispensável para o desprendimento das amarras ideológicas cartesianas e coloniais.

Não é possível coexistir Direitos Humanos com uma epistemologia estática, fechadae homogênea. Pelo contrário, ao falar em Direitos Humanos, tem-se em sua matriz ética a dialética, a memória e o reconhecimento das lutas sociais para a conquista de direitos ao longo da história, sem discriminação e exclusão. Os Direitos Humanos não admitem a visão etnocêntrica e restrita apenas a uma cultura. Ela pressupõe o diálogo intercultural a partir da hermenêutica diatópica e ecumênica entre povos, religiões, grupos sociais, cores, sexos que englobe todas as diferenças, unindo-as sob as suas similitudes de ser um humano.

A partir de uma educação jurídica emancipatória para os Direitos Humanos será possível questionar, filosoficamente e eticamente, a concepção liberal do eurocentrismo universalizador e homogeneizador, responsáveis pela criação da construção da subcidadania e das grandes periferias capitalistas. Busca-se o contrário, o pluralismo, a diversidade, a igualdade, a dinamicidade, o movimento. É a partir desse movimento pós-abissal que será possível resgatar o diálogo intercultural e a reafirmação e valorização dos diversos tipos de epistemologias.

Tão somente a partir da luta pelos Direitos Humanos, sobretudo para as minorias, será possível a viabilidade de uma efetiva democracia e a manutenção do Estado Democráticode Direito. Quanto isso:

Os direitos humanos são, a partir desse ponto de vista, direitos das gentes em cada um dos âmbitos da existência social [...]. Desse modo a exploração do trabalho de uns sobre os outros [...] é uma violação de direitos humanos. O patriarcalismo [...] a homofobia são uma agressão aos direitos humanos. [...] privatizar as instituições do estado em benefício de uns poucos é uma violação dos direitos humanos. O

Revista de Pesquisa e Educação Jurídica | e-ISSN: 2525-9636 | Encontro Virtual | v. 7 | n. 2 | 
controle da subjetividade, especialmente do conhecimento [...] é uma violação radical dos direitos humanos (QUIJANO, 2001, p. 13)

As práticas pedagógicas em educar em Direitos Humanos são atos decoloniais, uma vez que atravessará as linhas do "lado de lá" para o "lado de cá", de modo a atenuar o muro das violências e das exclusões que separam os dois mundos, instituída pelo paradigma dominante eurocêntrico. Educar para Direitos Humanos significa a construção de novas bases epistemológicas, uma mudança cultural das raízes incutidas e impostas no ideário social, demarcados por preconceitos, discriminações, exclusões, invisibilidades, pela não aceitação da diferença, do diferente. Almeja-se, por outro lado, a pluralidade, a inclusão, a diversidade cultural dos particularismos, das diversas formas de enxergar o mundo e de produzir conhecimentos (BENEVIDES, 2011).

A ecologia dos saberes traduz, sobretudo, a necessidade do rompimento das amarras tecnocratas e tradicionalista do ensino e da educação jurídica. Assim como todos os outros tipos de conhecimentos, o modo de ensinar o Direito também foi importado da Europa: um ensino ultraliberal, eurocêntrico, tradicionalista, tecnicista, acrítico e elitista. Infelizmente, muitas dessas características ainda se fazem presentes no ensino jurídico, o que inviabiliza o giro decolonial nas instituições de ensino de direito, tampouco a perpetuação desse movimento nas outras instâncias de formação, sobretudo a básica.

Os cursos de formação dos docentes, ao longo do tempo, foi marcado pelos vieses tecnicistas, na racionalidade instrumental, na concepção fragmentada das áreas do conhecimento, o que obsta a plena efetivação de uma Educação emancipatória em Direitos Humanos. Ademais, ressalta-se que:

[...] a formação política dos professores/as é, com frequência, negligenciada pelos cursos de formação inicial e até mesmo pelos agentes responsáveis pelas iniciativas de formação continuada desses profissionais. Existem poucos espaços, nos currículos da maior parte das escolas de formação de professores/as, destinados ao conhecimento e analise da realidade, a discussão sobre a politicidade do ato de educar, ou seja, sobre o "porque", o "para que", "a quem" e "contra o que" educar [...]. (NASCIMENTO, 2003, p. 118-119)

A prática pedagógica da educação para os Direitos Humanos enquanto uma prática emancipatória traz a experiência da afetividade de modo a compreender os problemas locais e novos modos de resolvê-los, de tal modo a transformar as situações jurídicas ali existentes. É nadar contra a corrente, ser uma fonte de resistência, um ideário contra 
hegemônico na luta daefetivação de direitos, na reinvindicação de políticas públicas mais básicas para a promoçãoda dignidade da pessoa humana.

Não se remonta a ideia de educação para os Direitos Humanos apenas nos cursos de Direito, como é, minimamente, esperado ser trabalhado de modo transversal e multidisciplinar, nas disciplinas teóricas e práticas, seja no ensino, na pesquisa e na extensão. É preciso, ainda, pensar numa Educação para os Direitos Humanos na base escolar, desde o primário até o Ensino Médio, para que haja a emancipação de meninos e meninas para romper com a mera transmissão do conhecimento de forma acrítica e reflexiva, como tem sido feito, mas que pode ser intermediado por alunos e alunas estudantes de Direito.

É na escola e nas instituições superiores que haverá a formação de um indivíduo autônomo, meio pelo qual garantirá sua dignidade por meio de um processo emancipatório. Dessa forma, Imannuel Kant (2005, p. 1) propôs uma revisão de artifícios que limitavam a emancipação de um indivíduo e questionava a possibilidade de encontrar uma solução a qual denominou como "menoridade":

Esclarecimento é a saída do homem de sua menoridade, da qual ele próprio é culpado. A menoridade é a incapacidade de fazer uso de seu entendimento sem a direção de outro indivíduo. O homem é o próprio culpado dessa menoridade se a causa dela não se encontra na falta de entendimento, mas na falta de decisão e coragem de servir-se de si mesmo sem a direção de outrem. (KANT, 2005, p. 1).

Um exemplo prático dessa parceria entre a universidade para com as escolas públicasseria a parceria da Faculdade de Direito de Vitória (FDV) e a Escola Estadual de Ensino Fundamental e Médio "Hunney Everest Piovesan", em um projeto intitulado "Direito e educação para os Direitos Humanos como práticas emancipatórias", com o primeiro tema gerador "Ideal de Gênero como Ideal de Justiça". Veja uma breve descrição do projeto, extraído do currículo lattes da Professora Elda Coelho de Azevedo Bussinguer:

Cuida-se de projeto de extensão vinculado ao Grupo de Pesquisa Políticas Públicas, Direito à Saúde e Bioética (BIOGEPE), da Faculdade de Direito de Vitória, coordenado pela Professora Elda de Azevedo Coelho Bussinguer. Possui por objetivo desenvolver práticas educativas por meio das quais se desvele consciência crítica nos participantes acerca de direitos fundamentais, com viés emancipatório e libertador. Coloca em prática a premissa de que o Direito é construído a partir de múltiplas fontes, em diálogo construtivo permanente entre diversas culturas e formasde saber. Portanto, busca contribuir para a formação de cidadãos conscientes e ativos, capazes de organizar-se coletivamente para

Revista de Pesquisa e Educação Jurídica | e-ISSN: 2525-9636 | Encontro Virtual | v. 7 | n. 2 | 
reivindicar direitos, seres humanos plenos e autônomos, cujas potencialidades possam afluir livremente. Tem como público-alvo a população em geral. Através dos sub-projetos, com objetivos específicos, serão definidos os públicos-alvo de cada iniciativa.

Ao se falar em Educação para os Direitos Humanos é a disseminação da cultura da alteridade, da inclusão, da mudança de paradigmas, em um processo que deve ser permanente, contínuo e global. A prática educacional, neste sentido, tem por obrigação em ser compartilhada, do professor para o aluno e do aluno para o professor, por se tratar de uma emancipação bilateral, em um formato holístico e horizontal.

Essa educação tem como objetivo profícuo em romper com os preconceitos de que Direitos Humanos seriam os direitos "dos manos", direitos de "bandidos", conforme vem sido amplamente divulgado. Na verdade, ao falar em Direitos Humanos, trata-se daqueles valores que são inatos a todos e quaisquer ser humanos, sem qualquer tipo de distinções, a fim de conferir-lhe a ciência e gozo de seus direitos à liberdade, à justiça, à igualdade e todos os direitos e garantias fundamentais previstos no artigo $5^{\circ}$ da Constituição Federal. É necessário que os centros de ensino básico às instituições de nível superior construam um projeto eco- político-pedagógico na perspectiva cidadã de Paulo Freire, a qual, segundo ele:

[...] se assume como centro de direitos, como um centro de deveres. A Escola Cidadã, então, é a escola que viabiliza a cidadania de quem está nela e de quem vem a ela. Ela não pode ser uma escola cidadã em si e para si. Ela é cidadã na medida emque se exercita na construção da cidadania de quem usa o seu espaço. A Escola Cidadã é uma escola coerente com a liberdade que, brigando para ser ela mesma, luta para que os educandos-educadores também sejam eles mesmos. E como ninguém pode ser só, a Escola Cidadã é uma escola de comunidade, de companheirismo. É uma escola que não pode ser jamais licenciosa nem jamais autoritária. É uma escola que vive a experiência tensa da democracia. (PAULOFREIRE, março de 1997. In: PADILHA, Paulo R., 2001 p.61; segunda orelha).

Diante o exposto, para que haja uma superação da colonialidade do poder e para a reafirmação das Epistemologias do Sul, é necessário que haja a efetivação dos movimentos anti-cartesianos, pós-abissais e do giro decolonial. A partir disso, terá que a educação para os Direitos Humanos será uma prática emancipatória e uma estratégia de promoção de cidadania e de colocar, de fato, em prática os direitos e garantias fundamentais, para que não seja uma mera letra morta da lei. 


\section{CONSIDERAÇÕES FINAIS}

Torna-se evidente, portanto, que a forma de pensar e de produzir o pensamento da América do Sul sofre grande influência do colonialismo europeu, trazendo o pensamento arcaico, linear, cartesiano, homogêneo, acrítico, que gerou grandes invisibilidades e exclusõesde povos e culturas que aqui habitavam.

Resta claro que a única forma de valorização e reafirmação das Epistemologias do Sul é o investimento em políticas públicas de educação, da base ao ensino superior, para os Direitos Humanos enquanto uma prática emancipatória compromissada com a afirmação da cidadania. Apenas por intermédio de uma educação libertadora será possível compreender os particularismos e características genuínas de cada povo, por intermédio de um diálogo intercultural, que reconheça as diferenças e que propiciem um ideal de igualdade e de justiça.

Não se trata de menosprezar um conhecimento em detrimento do outro, da ânsia de tornar as Epistemologias do Sul igual o superiores às da Europa, mas sim compreender que cada cultura, cada modo de produzir pensamento e de convivência possuem suas características próprias e podem e devem ser respeitadas, não admitindo, assim, a supremacia de um povo sobre o outro.

A pesquisa científica, sobretudo do Sul, não deve se tornar um discurso de papel, que fica engavetado ou apenas nas estantes das bibliotecas. A pesquisa científica do Sul deve ser elaborada a partir da produção de pensamento por várias vozes, várias mãos, que reconheça a pluralidade de ideias e de sentidos dos povos, dos diversos direitos previstos nas constituições, independentemente de lado ou de matriz ideológica, como uma alma viva da sociedade, uma prática efetiva. A diversidade epistemológica, a partir da educação emancipatória para os Direitos Humanos, é uma forma de, em vez da invisibilidade, garantir a visibilidade, em vez da exclusão, garantir a inclusão, ao invés das relações verticalizadas, garantir as relações horizontalizadas e não cartesianas para o cumprimento das promessas constitucionais.

É prudente o reestabelecimento do diálogo, a partir de práticas descolonizadoras e decoloniais, vivenciando a lógica da ética da alteridade, que se construa uma sociedade mais justa e igualitária, através dos princípios da solidariedade social e da dignidade da pessoa humana. É preciso realocar as ideias puramente coisificadas para reconhecer o outro 
como parte de nós, seja lá qual for a raça, credo, sexo, origem, ou outra categorização excludente, para haver a validação dos saberes locais e da produção de identidade e subjetividades dos sujeitos sociais.

Para muitos, falar sobre isso é algo óbvio, mas infelizmente não é. Basta sair da própria "bolha" e buscar enxergar as desigualdades que foram internalizadas em nosso seio social e ver que, além de não haver uma educação para os Direitos Humanos, não há sequer a promoção dos direitos humanos mais básicos dos indivíduos como o direito à habitação, à moradia, ao saneamento básico, ao trabalho decente, dentre outros.

Não basta haver pesquisas científicas sobre este tema. É preciso sair do comodismo, da zona de conforto e dos privilégios que você, leitor, tem, ao ter um tempo para ler o presente artigo, enquanto as mazelas do neoliberalismo e do neoconservadorismo se alastra sobre todo o mundo causando forme, desemprego e a escassez de direitos que demoraram em serem conquistados. É preciso fazer a diferença, é preciso ser colonial, é preciso ter uma educação libertadora e emancipatória para os Direitos Humanos enquanto estratégia de afirmação de cidadania e reconhecimento do outro como ser humano, titular de todos os direitos e garantias fundamentais que foram positivados. 


\section{REFERÊNCIAS}

ARISTÓTELES. Ética a Nicômaco. Livro V. São Paulo: Martin Claret, 2016.

BALLESTRIN, Luciana. América latina e o giro decolonial. Revista Brasileira de CiênciaPolítica. Disponível em:

<https://www.scielo.br/j/rbcpol/a/DxkN3kQ3XdYYPbwwXH55jhv/> Acesso em 02 set.2021.

BENEVIDES, Maria Victória. Educação em Direitos Humanos: de que se trata? Palestra deabertura do Seminário de Educação em Direitos Humanos, São Paulo em 18/10/2012. Disponível em: <www.hottopos.com/convenit6/victoria.htm>. Acesso em: 25 ago. 2011.

BOURDIEU, Pierre. A juventude é apenas uma palavra. In: BOURDIEU, Pierre. Questão desociologia. Rio de Janeiro: Marco Zero, 1983.

BOURDIEU, Pierre. A escola conservadora: as desigualdades frente à escola e à cultura. In: NOGUEIRA: Maria Alice; CATANI, Afrânio. Escritos de Educação. São Paulo: Vozes, 1998.p. 39-64.

CARVALHO, Rayann Kettuly Massahud. Colonialidade, democracia e o risco permanente de ruptura: uma reflexão a partir da obra de A. Quijano. Revista de Ciências do Estado. Belo Horizonte: v. 6, n. 1,e26617. ISSN: 2525-8036.

KANT, Immanuel. Resposta à pergunta: o que é Esclarecimento? Textos Seletos. Tradução:Floriano de Sousa Fernandes. 3. ed. Petrópolis: Vozes, 2005, p. 63-71.

LAKATOS, Eva Maria; MARCONI, Marina de Andrade. Fundamentos da MetodologiaCientífica. 8. Ed. São Paulo: Atlas, 2019.

MIGNOLO, Walter D. Desobediência epistêmica: a opção descolonial e o significado deidentidade em política. Cadernos de Letras da UFF: Dossiê: literatura, Línguas e Identidades. Rio de Janeiro: Cadernos de Letras da UFF, 2008.

MIGNOLO, Walter D. Os esplendores e as misérias da "ciência": colonialidade, geopolítica do conhecimento e pluriversalidade epistémica. In: SANTOS, Boaventura de Sousa (Org.).Conhecimento prudente para uma vida decente: um discurso sobre as ciências revisitado. 2. ed. São Paulo: Cortez, 2006.

NASCIMENTO. Maria das Graças C. de A. A dimensão política da formação de professores/as. IN: CANDAU. Vera; SACAVINO. Susana. Educar em direitos humanos: construir democracia. 2 ed. Rio de Janeiro: DP\&A, 2003.

PADILHA, Paulo R. Relação pedagógica na sala de aula. In: Anais do $6^{\mathbf{0}}$ Seminário deEducação “Transversalidade no espaço escolar". Criciúma, 2000a, pp. 19-47.

QUIJANO, Anibal. Colonialidade do poder, eurocentrismo e América Latina. In: A colonialidade do saber: eurocentrismo e ciências sociais. Perspectivas latinoamericanas.

Revista de Pesquisa e Educação Jurídica | e-ISSN: 2525-9636 | Encontro Virtual | v. 7 | n. 2 | 
Edgardo Lander (org). Colección Sur Sur, CLACSO, Ciudad Autónoma de Buenos Aires, Argentina. setembro 2005.

QUIJANO, Anibal. La modernidad, el capital y América Latina nacieron en el mismo día. Entrevista deNora Velarde. ILLA, Revista del Centro de Educación y Cultura, n. 10, jan., p. 42-57, 1991.

QUIJANO, Anibal. Os fantasmas da América Latina. In: NOVAES, Adauto (org.).

Oito visões daAmérica Latina. São Paulo: SENAC, 2006.

QUIJANO, Anibal. Poder y Derechos Humanos. In: SEVILLA, Carmen Pimentel (comp.). Poder, SaludMental y Derechos Humanos. CECOSAM. Lima, Perú. 2001.

RICHARDSON, Roberto Jarry. Pesquisa Social: métodos e técnicas. 4. ed. São Paulo: Atlas, 2017.

SANTOS, Boaventura de Sousa. A gramática do tempo: para uma nova cultura política. 3.ed. São Paulo: Cortez, 2008.

SANTOS, Boaventura de Sousa. A Universidade do século XXI: para uma reforma democrática e emancipatóriada Universidade. 3. Ed. São Paulo: Cortez, 2011. SANTOS, Boaventura de Sousa. Epistemologies of the South: Justice Against Epistemicide. Boulder: ParadigmPublishers, 2014.

SANTOS, Boaventura de Sousa. Para além do pensamento abissal: das linhas globais a uma ecologia de saberes. In:SANTOS, Boaventura de Sousa, MENESES, Maria Paula (orgs.). Epistemologias do Sul. São Paulo: Cortez, 2010.

SANTOS, Boaventura de Sousa. Toward a New Common Sense: Law, Science and Politics in ParadigmaticTransition. Nova Iorque: Routledge.

SANTOS, Boaventura de Sousa. Uma concepção multicultural de direitos humanos. Lua

Nova: Revista de Culturade Política, São Paulo, n.39, p.105-124, 1997.

SANTOS, Boaventura de Sousa. Um discurso sobre as ciências. 10. ed. Porto:

Afrontamento, 2009.

SEGATO, Rita L. Aníbal Quijano y la Perspectiva de la Colonialidad del Poder. In: SEGATO, Rita. La Crítica de la Colonialidad en Ocho ensayos y una Antropología porDemanda. Buenos Aires: Prometeo, 2015.

SILVA, Fabricio Pereira; BALTAR, Paula; LOURENÇO, Beatriz. Colonialidade do Saber, Dependência Epistêmica e os Limites do Conceito de Democracia na América Latina.

Revistade Estudos e Pesquisas sobre as Américas. V. 12, 1 ed. 2018. 